\title{
ENVIRONMENT CONSCIOUS CERAMICS (ECOCERAMICS)
}

\section{Singh}

Dynacs Engineering Company Inc.

MS 106-5, Ceramics Branch

NASA Glenn Research Center

Cleveland, $\mathrm{OH} 44135$

\section{ABSTRACT}

Environment conscious ceramics (Ecoceramics) are a new class of materials, which can be produced with renewable natural resources (wood) or wood wastes (wood sawdust). Silicon carbide-based ecoceramics have been fabricated by reactive infiltration of carbonaceous preforms by molten silicon or siliconrefractory metal alloys. These carbonaceous preforms have been fabricated by pyrolysis of solid wood bodies at $1000^{\circ} \mathrm{C}$. The fabrication approach, microstructure, and mechanical properties of $\mathrm{SiC}$-based ecoceramics are presented. Ecoceramics have tailorable properties and behave like ceramic materials manufactured by conventional approaches.

\section{INTRODUCTION}

Silicon carbide-based ceramics have been utilized since the beginning of the $20^{\text {th }}$ century as heating elements. However, tremendous growth in research and development activities in this area has occurred in the last forty years. These materials have high strength, good oxidation and corrosion resistance, high thermal conductivity, and good thermal shock resistance. A number of manufacturing approaches have been used to fabricate these materials including hot pressing/hot isostatic pressing, sintering, reaction bonding/reaction forming, polymer pyrolysis, and chemical vapor deposition. Hot pressing and sintering approaches require significant consumption of energy while CVD and polymer pyrolysis techniques generate liquid and gaseous chemical by-products. The reaction bonding techniques typically utilizes silicon carbide and carbon powder combined with polymer binders while resin/pore former derived preforms are used in the reaction forming techniques. The production of silicon carbide powder is energy consuming. The pyrolysis of resin systems produces chemical byproducts, which have to be collected for disposal.

This is a preprint or reprint of a paper intended for presentation at a conference. Because changes may be made before formal publication, this is made available with the understanding that it will not be cited or reproduced without the permission of the author. 
Environment conscious ceramics (Ecoceramics) are a new class of materials, which can be produced with renewable resources (wood) and wood wastes (wood sawdust). The wood sawdusts are generated in abundant quantities by sawmills. On the other hand, natural woods of various types are available throughout the world. Wood has been known to be one of the best and most intricate engineering materials created by nature and known to mankind [1-2]. The biomorphic ceramic materials, fabricated via the pyrolysis and infiltration of natural wood-derived preforms, have tailorable properties with numerous potential applications. The experimental studies conducted to date on the development of materials based on biologically derived structures indicate that these materials behave like ceramic materials manufactured by conventional approaches [3-10]. These structures have been shown to be quite useful in producing porous or dense materials having various microstructures and compositions $[3,4,6,7,10]$.

In the present work, SiC-based environment-conscious ceramics have been fabricated by the molten silicon infiltration of porous carbonaceous preforms. These preforms have been fabricated by the pyrolysis of natural wood. In this paper, the fabrication approach, microstructure, and mechanical properties of SiCbased ecoceramics are described.

\section{EXPERIMENTAL PROCEDURE}

In this study, different types of wood specimens and wood saw dusts were used for the fabrication of carbonaceous preforms. A schematic of the fabrication process is given in Fig. 1. The wood pieces were pyrolyzed in a furnace up to $1000^{\circ} \mathrm{C}$ in a flowing nitrogen atmosphere. Porous preforms were also fabricated from the wood sawdust but results will be reported elsewhere [10]. The weight and dimensional changes were recorded after pyrolysis. The pyrolyzed preforms were infiltrated with silicon or silicon based alloys in a graphite element fumace under vacuum. The infiltration time and temperature depend on the melting point of the infiltrants and dimensions and properties of the preforms. For silicon infiltration, porous preforms were infiltrated at $1450^{\circ} \mathrm{C}$ for 30 minutes.

Although a wide variety of materials were fabricated using this approach, detailed microstructural characterization and the mechanical properties of a material fabricated by the infiltration of molten silicon into a pyrolyzed Indian Mango Wood preform will be presented. After the infiltration, specimens were machined for microstructural and mechanical property studies. The final product was a cellular structure with elongated areas of $\mathrm{SiC}$ and $\mathrm{Si}$. Samples were crosssectioned and polished for metallographic studies. Microstructural characterization was performed on the as-fabricated and deformed samples using optical and scanning electron microscopy. 


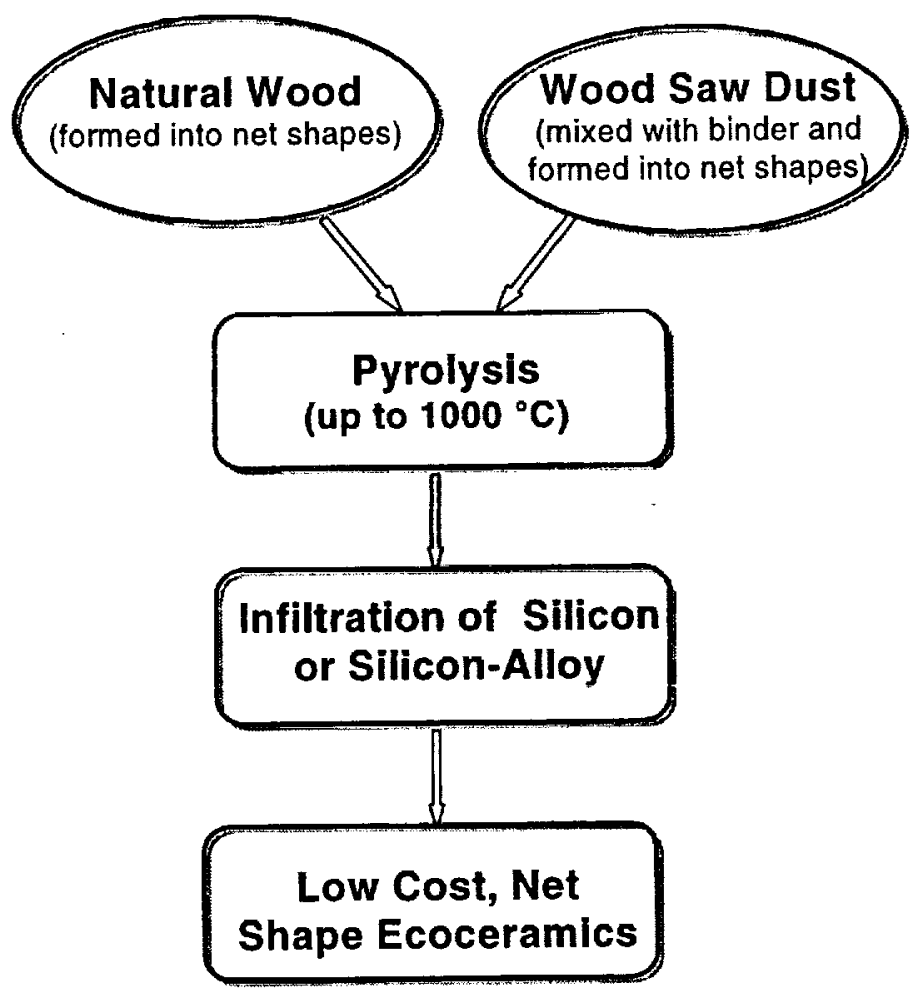

Fig. 1: Schematic of the fabrication process.

For the mechanical property measurements, parallelepipeds of $3 \times 3 \times 5 \mathrm{~mm}$, with the longer axis parallel or perpendicular to the cell structure were machined from bulk materials. The specimens were tested in compression at a constant strain rate of $2 \times 10^{-5} \mathrm{~s}^{-1}$ for temperatures ranging from room temperature to 1350 ${ }^{\circ} \mathrm{C}$, in air. Testing was performed using a screw driven Instron universal testing machine model 1185 with a furnace mounted on its frame. Alumina rods with $\mathrm{SiC}$ pads were used. The load/time behavior was monitored with a chart recorder.

\section{RESULTS AND DISCUSSION}

A wide variety of wood specimens were pyrolyed and infiltrated in this study. Scanning electron micrographs of fracture surfaces of some porous wood-derived preforms are given in Fig. 2. These micrographs show a wide variation in the microstructure and density of the different types of wood. The variation of preform microstructure and properties can be utilized to produce final materials with controlled microstructure, composition, and phase morphologies. The pyrolysis shrinkage, composition, and final density of preforms vary greatly depending on the type of wood. 


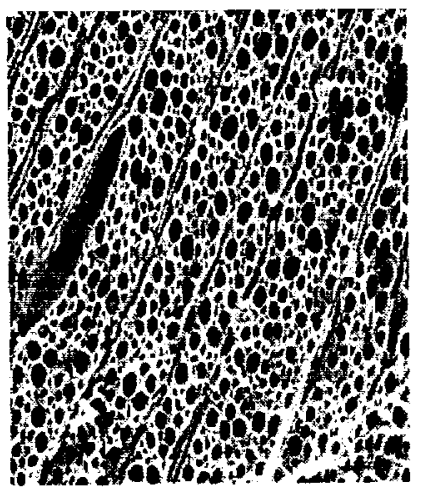

Brazilian Rosewood (300 X)

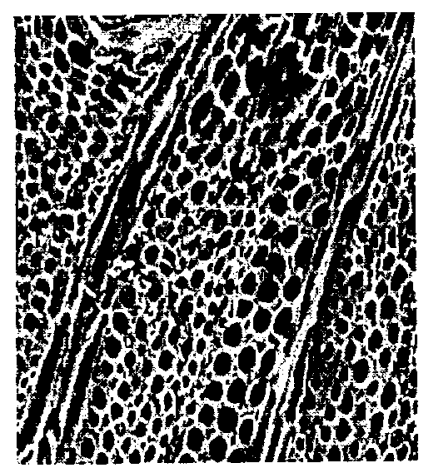

African Bubinga (100 X)

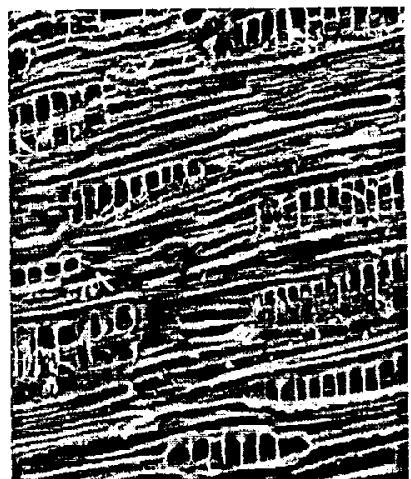

African Zebra (300 X)



Pau Lope $(200 \mathrm{X})$

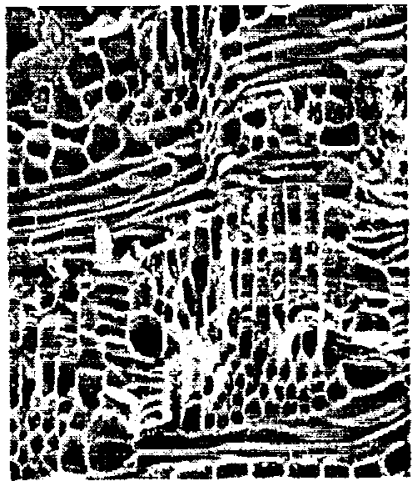

Ceylon Satinwood (300 X)

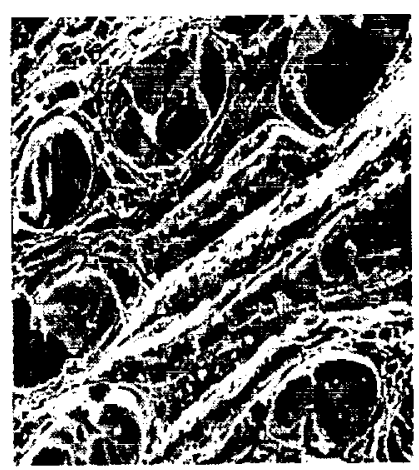

Australian Jarrah (200 X)

Fig. 2: Microstructure of porous carbon preforms obtained from the pyrolysis of different types of wood.

The microstructures of a pyrolyzed Indian Mango Wood preform and the final materials after infiltration are shown in Fig. 3 (a) and (b,c), respectively. There are large silicon areas and regions where the silicon is finely distributed. It is important to note that the microstructure parallel and perpendicular to fiber axis is different. The bulk density of the as-fabricated material, measured by the Archimedes method, was $2.69 \pm 0.01 \mathrm{gm} / \mathrm{cm}^{3}$.

The stress-strain plots of the constant strain rate experiments are shown in Fig. 4. At room temperature, the stresses on the sample increased until failure, without load drops typical of fiber reinforced composites [8]. The strength was very anisotropic, being about four times higher when the compression was done parallel to the axial direction [8] indicating the importance of the orientation of cylindrical cores of silicon carbide on the strength of the material. At high temperatures there is a yield after $1-2 \%$ of strain, with the strength of the material 
aproximately constant after this point. The experiments were stopped at strains around $10 \%$. The deformed samples showed microcracking, but catastrophic crack propagation did not occur during the tests (sometimes the samples broke while being separated from the $\mathrm{SiC}$ pads). The high strengths at temperatures very close to the melting point of silicon is attributed to the continuous silicon carbide (SiC) network with $\mathrm{Si}$ filling up the pores. This microstructure cannot be deformed without the deformation of both components.

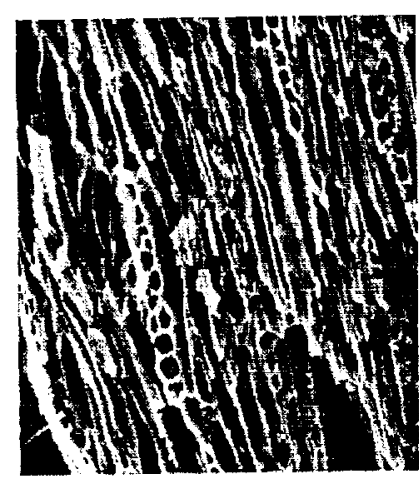

(a)

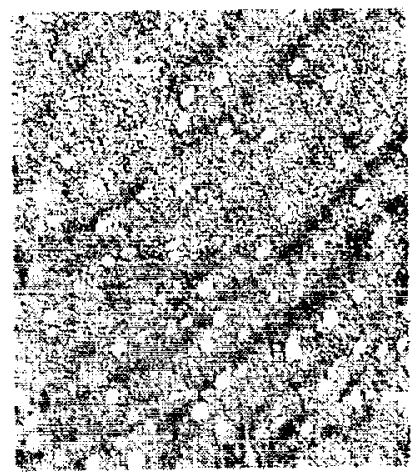

(b)

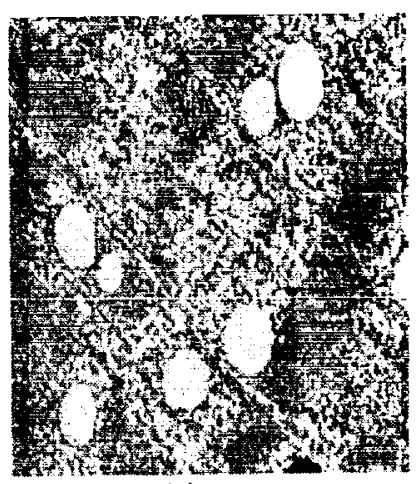

(c)

Fig 3. Micrographs of the (a) Indian Mango wood preform $(500 \mathrm{X})$ in axial direction; and $(b, c)$ as-fabricated material, perpendicular to the axial direction (50 and $500 \mathrm{X}$ ). White areas are silicon and gray areas are silicon carbide.

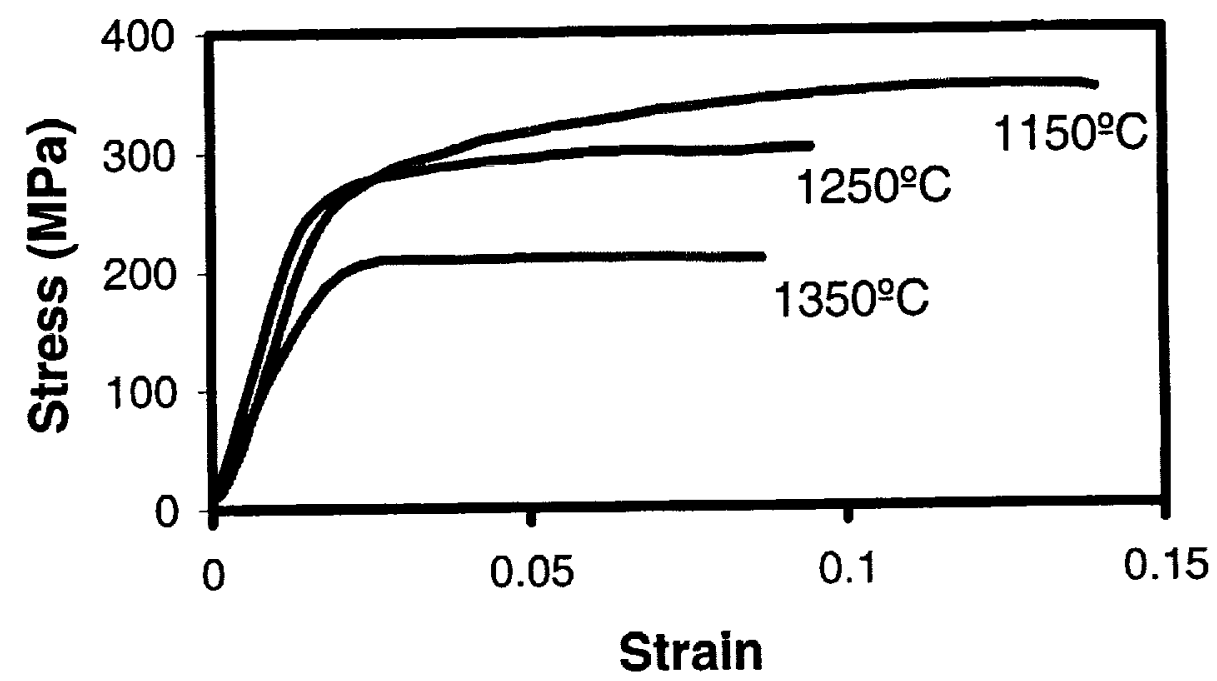

Fig. 4 - Stress-strain plot of the compression tests at high temperature, with compression parallel to the axial direction. 


\section{CONCLUSIONS}

Environment conscious $\mathrm{SiC}$-based ceramics have been fabricated from renewable natural resources. These ceramic materials have a uniform microstructure that resembles the microstructure of the wood preform. They behave as a silicon carbide-based cellular solid, reaching very high strengths. The low cost, flexibility to fabricate complex shapes, and the availability of unique microstructures in nature makes this fabrication technique very promising for producing materials suitable for structural and lightweight applications.

\section{ACKNOWLEDGMENTS}

Author would like to thank Mr. Richard Dacek for help in experimental work and to Mr. J.D. Kiser for critically reading the manuscript. Assistance of Professor Julian Martínez-Fernández from University of Seville, Spain in performing high temperature compression tests is also acknowledged.

\section{REFERENCES}

1"Wood Handbook- Wood as an Engineering Material", Forest Products Laboratory, USDA Forest Service, Madison, WI, General Technical Report, FPLGTR-113 (1999).

2"Concise Encyclopedia of Wood and Wood-Based Materials", A.P. Scniewind, Ed., Pergamon Press, NY (1989)

${ }^{3}$ T. Ota, M. Takahashi, T. Hibi, M. Ozawa, and H. Suzuki, "Biomimetic Process for Producing SiC Wood", J. Am. Ceram. Soc., 78, 3409 (1995).

${ }^{4}$ P. Greil, T. Lifka, and A. Kaindl, "Biomorphic Silicon Carbide Ceramics from Wood : I and II, J. Europ. Ceram. Soc., 18, 1961 (1998).

${ }^{5}$ D.-W. Shin, S.S. Park, Y.-H. Choa and K. Niihara, "Silicon/Silicon Carbide Composites Fabricated by Infiltration of a Silicon Melt into Charcoal", J. Am. Ceram. Soc., 82, 3251 (1999).

${ }^{6}$ H. Sieber, A. Kaindl, D. Schwarze, J-P. Werner and P. Greil, "Light-weight Cellular Ceramics from Biological Derived Preforms", in Ceramics Forum International (2000) to be published.

${ }^{7}$ H. Sieber, A. Kaindl and P. Greil, "Biostructure Derived Ceramics", in "Ceramic Engineering and Science Proceedings (2000).

${ }^{8}$ J. Martínez-Fernández, F. M. Valera-Feria, M. Singh, "High Temperature Compressive Mechanical Behavior of Biomorphic Silicon Carbide Ceramics" submitted to Scripta Materialia (2000).

${ }^{9} \mathrm{~J}$. Martínez-Fernández, F. M. Valera-Feria, M. Singh, "Microstructure and Thermomechanical Characterization of Biomophic SiC-Based Ceramics" submitted to Proc. of Int. Conf. on Ecomaterials, Ottawa, Canada (2000).

${ }^{10} \mathrm{M}$. Singh, Unpublished work (2000). 